\title{
Fruit and Vegetable Consumption by Louisiana's Youth: Strategies to Increase Intake and Reduce Obesity
}

\author{
Holly S. Kihm, PhD, CCLS \\ Associate Professor \\ Southeastern Louisiana University \\ Box 10863, Hammond, LA 70402, USA \\ Phone: 985-549-2309 \\ Dan Hollander, PhD \\ Professor \\ Southeastern Louisiana University \\ Box 10863, Hammond, LA 70402, USA \\ Phone: 985-549-3870 \\ Heidi Kulkin, PhD, LCSW-BACS \\ Associate Professor \\ Southeastern Louisiana University \\ Box 10863, Hammond, LA 70402, USA \\ Phone: 985-549-2309 \\ Peggy Rolling, PhD, CFLE \\ Professor \\ Southeastern Louisiana University \\ Box 10863, Hammond, LA 70402, USA \\ Phone: 985-549-2309
}

\begin{abstract}
Increased fruit and vegetable consumption (FVC) is recommended by the Center for Disease Control (CDC) for combating obesity among children (CDC, 2015). Despite the recommendations, children consume inadequate amounts of fruits and vegetables (Glen, Thomas, Loebach, Gilliland, \& Gobert, 2014; Neville, McKinley, \& Draffin, 2015). The purpose of this study was to evaluate the factors that influence FVC among children in Louisiana. Results showed that both boys and girls reported fairly consistent FVC up until the 5th grade. Beyond the 5th grade, race, gender, and age became significant factors for determining FVC. Additionally, older children had higher BMI scores when compared to younger children. The findings may provide future policy makers and public health campaigns with valuable input on how to increase FVC.
\end{abstract}

Keywords: Youth, Obesity, Nutrition, Fruits, Vegetables, Strategies

\section{Introduction}

The American Association of Family and Consumer Sciences (AAFCS) has been engaged in an initiative, "FCS Fit," which aims to increase the global health and wellness of families. Though "FCS Fit" may be applied to many branches of Family and Consumer Sciences, the purpose of this study was to discuss fruit and vegetable consumption, and its importance for having a healthy diet. FCS educators have a unique opportunity to teach families not only about the importance of fruit and vegetable consumption (FVC), but to also show families how to grow produce and prepare it in ways that appeal to all members of the family.

Increased FVC is recommended by the Center for Disease Control (CDC) for combating obesity among children(CDC, 2015). Despite the recommendations, children consume inadequate amounts of fruits and vegetables (Glen, Thomas, Loebach, Gilliland, \& Gobert, 2014; Neville, McKinley, \& Draffin, 2015). The purpose of this study was to evaluate the factors that influence FVC among children in Louisiana. 
Results showed that both boys and girls reported fairly consistent FVC up until the $5^{\text {th }}$ grade. Beyond the $5^{\text {th }}$ grade, race, gender, and age became significant factors for determining FVC. Additionally, older children had higher BMI scores when compared to younger children. The findings may provide future FCS educators with valuable input on how to increase FVC.

In Louisiana, obesity rates for children are among the highest in the nation at approximately 35\%, almost double the national average (Singh, Kogan, \& Van Dyck, 2010).Children and youth face several negative health-related outcomes as a result of being overweight and obese including type 2 diabetes, cardiovascular disease, and high blood pressure (CDC, 2015). Ogden, Carroll, Kit, and Flegal (2014) reported that children and youth who were overweight or obese experienced more breathing problems, and suffered from joint problems more often than children and youth not categorized as overweight or obese.

As a direct result of the increase in negative health outcomes, medical costs associated with treating children and youth for obesity-related conditions has risen at an exorbitant rate. Dietz and Wang (2002) found that during 19791981, hospitals in the nation spent approximately 35 million dollars to treat obese youth aged 6 to 17. Less than20 years later, hospital costs associated with youth obesity increased to over 127 million dollars from 1997-1999. Currently, the nation spends 190.2 billion annually on health care costs related to obesity, of which $\$ 14$ billion is associated with childhood obesity (Cawley \& Meyerhoefer, 2012).

Negative self-image, low self-esteem, eating disorders, and a low health-related quality of life have also been cited as detrimental outcomes related to overweight and obesity among youth (Davison \& Birch, 2001; Strauss, 2000). In their review of the literature, Puhl and King (2013) found that being overweight or obese as a child was associated with "depression, anxiety, low self-esteem, body dissatisfaction, suicidal ideation, and maladaptive eating behaviors." Similar results were found by Williams, Fournier, Coday, Richey, Tylavsky, and Hare (2013) when they assessed the self-esteem and rates of bullying and peer victimization of overweight children (aged 5-7). The study showed that higher BMI was associated with lower self-esteem for both boys and girls, and that girls with a higher BMI reported significantly more incidences of being bullied when compared to their peers with lower BMIs. For the aforementioned reasons, being overweight or obese at a young age can have a negative effect on an individual's wellbeing. It is therefore imperative that more research be performed to spotlight what measures must be taken to decrease this epidemic among youth in Louisiana.

The purpose of this study was to evaluate the factors that influence FVC among children in Louisiana. There are many positives to increasing FVC, it can lower the risk of developing many chronic diseases associated with being overweight and obese, and help with body weight management (USDA/DHH, 2010). The USDA and various other studies have cited an increase in FVC as an effective mode in decreasing obesity among youth in the nation. Findings from this study could provide Family and Consumer Science educators insight to what factors impede children from receiving the recommended rates of FVC. An increase in FVC among children in the state could potentially lead to a significant decrease in the high prevalence of obesity that threatens this young population.

\section{Methods}

\subsection{Participants}

All study protocol and procedures were approved by a university Institutional Review Board and the principal of the school where the study took place. Parents of participants provided written consent and all children provided verbal assent prior to data collection. In total, two-hundred and twenty-six children, in grades $\mathrm{K}$ though $8^{\text {th }}$, participated in the study (Table 1).Most of the study participants $(23.5 \%)$ were in $3^{\text {rd }}$ or $4^{\text {th }}$ grade, and of all the grades assessed, kindergartners were the least representative of the sample, with only $9.3 \%$ taking part in the study. There were approximately the same number of boys $(50.4 \%)$ and girls $(49.6 \%)$ in the study. In terms of race, the majority of participants were Caucasian (65.0\%), and only $19.9 \%$ of the population identified as being African American. Of all the ethnicities surveyed, students of Asian descent made up the smallest percentage (6.7\%), followed by students of Hispanic descent with $8.4 \%$.

Table 1. BMI for School by grade

\begin{tabular}{|l|l|l|l|}
\hline & Boys & Girls & Entire School \\
\hline $\mathrm{K}$ & 15.34 & 13.38 & 15.25 \\
\hline $1-2$ & 17.28 & 18.57 & 17.35 \\
\hline $3-4$ & 17.50 & 21.12 & 19.01 \\
\hline $5-6$ & 18.72 & 20.77 & 20.15 \\
\hline $7-8$ & 18.73 & 23.79 & 21.70 \\
\hline
\end{tabular}


The parish in which the school of interest resides has been identified as an underserved community, with $43 \%$ of children living in single-parent homes, and over 9,500 (32.0\%) children living in poverty. Around $82 \%$ of children that attend the school receive free and reduced lunch assistance, much higher than the state average of 69.9\% (National Center for Education Statistics, 2016). In 2013, it was estimated that $21.7 \%$ of residents in the parish lived in poverty, compared to the state average of $19.8 \%$. The average household income in 2015 for the parish was $\$ 53,062$, with a per capita income of only $\$ 21,262$ (National Center for Children in Poverty, 2016).

Due to its lack of access to affordable fruits, vegetables, and other healthy foodstuffs, the parish has also been identified as a "food desert" (USDA/DHH, 2010). Instead of an abundance of healthy eateries, the parish is flooded by fast food chains that serve up cheap meals with little to no nutritional value. Living in the midst of a food desertmakes it difficult for children and youth to obtain the daily recommended servings of fruits and vegetables.

\subsection{The Instruments}

Anthropomorphic assessments for the study population were recorded using a wall height chart that measured to the nearest $1 / 4$ inch and a digital health-o-meter electronic scale (Health-o-meter 349LX medical grade) that recorded weight to the nearest hundredth of a pound. From these assessments, BMI was calculated differently than it would have been for adults. The CDC uses BMI age and sex-specific percentiles for children and teens. Thus BMI was determined by dividing a participant's weight in pounds (lbs), by height in inches (in) squared, and multiplying by a conversion factor of 703. This technique standardizes the changes that occur during normal development and the amount of body fat changes that occur with age. Since the amount of body fat differs between girls and boys, the CDC translates BMI numbers into percentiles taking into account gender and age. Along with obtaining age and sex-specific BMI numbers, the study also stratified BMI by ethnicity before storing scores in the study data set.

Two surveys were developed for the study, one measured FVC and the other measured the physical activity levels of study participants. For the purpose of this paper, only results from the FVC survey will be discussed. The FVC survey contained pictures of fruits and vegetables, such as broccoli and peaches, followed by a brief caption where children were asked questions with relation to how many fruits and vegetables they had eaten the day before. The pictures were added to the questionnaire as a guide for younger children with very basic reading comprehension skills. To answer the questionnaire, students were instructed to circle the number that corresponded with their reported FVC. In addition to the surveys, researchers also interviewed students individually to capture study data.

\subsection{The Procedure}

Contact was made with the school of interest to coordinate assessments, and three days were scheduled for data collection. University students were recruited to aid with questionnaire administration, and were assigned to specific assessment stations. The university students were also instructed on proper measurement techniques for height and weight, which they collected prior to commencing the study.

At the assessment stations, each student was in charge of collecting data from several teams of four to five children. The teams of participants moved from one station to the next until the entire grade had completed all study measures. The assessments were performed during regular physical education classes and free activities were provided after completion of the assessments. Any child who did not wish to participate was given a chance to withdraw. Three students declined study involvement and eleven students had scheduling conflicts that did not allow them to participate.

\section{Results}

\subsection{Data Analysis}

Detailed BMI analysis showed that a significant difference was observed for BMI across grades ( $\mathrm{F}=11.93)$ in the expected direction, $\mathrm{p}<0.001$. Asthe students aged, their BMI increased, suggesting an intrinsic relationship between the two variables (Table 1). As demonstrated using a Scheffe's post hoc comparison, children in kindergarten had significantly lower BMI levels than children in the $3^{\text {rd }}-8^{\text {th }}$ grades $(\mathrm{p}<0.01)$.

The relationship between grade, sex, and ethnicity and their individual impact on BMI and FVC was determined using the nonparametric Kruskal-Wallis analyses (Table 2). The data displayed boys in the study having a significantly lower BMI than their female counterparts $(\mathrm{t}-4.8, \mathrm{p}<0.0001)$, with the average BMI for girls in $7^{\text {th }}$ to $8^{\text {th }}$ grade at approximately 23 versus the average BMI for boys of the same age averaging at 19.5 . 
Table 2. Kruskal-Wallis Analyses for Sex and Grade

\begin{tabular}{|c|c|c|c|c|}
\hline & BMI & veg & Fruit & type snack \\
\hline $\begin{array}{c}\text { Analysis for } \\
\text { Sex }\end{array}$ & $19.20^{* * *}$ & $5.78^{*}$ & 0.290 & 0.50 \\
\hline $\begin{array}{c}\text { Analysis for } \\
\text { Grade }\end{array}$ & $53.26^{* * *}$ & $13.07^{* *}$ & $14.80^{* *}$ & $14.56^{* *}$ \\
\hline \\
$p<.001^{* * *}, p<.01^{* *}, p<.05^{*}$
\end{tabular}

Among participants, a consistent trend of increased consumption of fruit occurred until the $5^{\text {th }}$ and $6^{\text {th }}$ grade. While for vegetables, there was a consistent trend of increased consumption until the $7^{\text {th }}$ and $8^{\text {th }}$ grade. Also important to note, the girls in the study reported eating more vegetables $(t=2.3, p<0.05)$ than their male counterparts.

Fruit consumption was significantly different based on race, $\mathrm{p}<0.006$. Caucasian children reported higher fruit consumption when compared to their African American, Hispanic and Asian peers. However, there were no significant differences in relation to race when observing each participant's vegetable consumption.

\section{Discussion}

By better understanding how grade, sex, and ethnicity influence the relationship between FVC and BMI among participants surveyed, the results discovered by the study can be used in developing future interventions/campaigns aimed at improving FVC among children and youth in Louisiana.

The results showed that girls in the study had significantly higher BMI levels when compared to the boys in the study. Even despite the fact that girls reported eating more vegetables than boys. Given the widely accepted theory that increased FVC correlates with lower BMI levels, it would be expected to see the opposite correlation between vegetable consumption and BMI levels among girls in the study. However, these findings do support results found by other studies which suggest that FVC does not always correlate with healthier weight, primarily with the consumption of vegetables. Researchers at Ohio University observed 6,500 children aged 2 to 18, and noted that while consumption of vegetables was higher among 12 to 18 year olds, fried potatoes constituted about 46 percent of their total vegetable consumption (2009). The varying results indicate a need to closely monitor how fruits and vegetables are prepared and consumed, particularly for adolescents.

The data also captured the fact that while girls reported eating more vegetables than boys, there was no significant difference in fruit consumption among genders. When looking at potential ethnic influences on FVC, data showed that Caucasians ate more fruit than the other groups studied. This finding highlights the need to further explore why the discrepancy exists, and how to best encourage an increase in FVC among other ethnicities.

The mean BMI for the sample was 21.3, which is above the national threshold of 19.5 for overweight status (CDC, 2014). Because the state of Louisiana has reported a mean level of obesity for children averaging about $35 \%$, it was not surprising to see this sample surpass the threshold for overweight and obesity status.

\subsection{Limitations}

As with all research, there were a few limitations in this study that must be accounted for. It is important to note that the school of interest was the highest academic performer in the parish, with relatively few students qualifying for free and reduced lunches and breakfasts. Thus, while the study demonstrated that children from the school had a high probability of being overweight or obese, it is likely that this sample was not completely representative of the larger population of the parish's primary and secondary school students based on the socioeconomic status of many of the students.

Another limitation to account for was that the majority of participants in the study were of Caucasian descent, and therefore the results may not be generalizable to all children in the state of Louisiana. However, being that $63.4 \%$ of the state identifies as being "white," the results from this study are highly representative of the state's overall population. Additionally, most of the data obtained was based on self-report surveys which could lead to different forms of self-report bias. Nevertheless, this method of data collection is highly used among researchers working with this age group.

\section{Conclusions}

FCS educators, especially educators who serve rural, or under-served populations, have an opportunity to provide tools to increase FVC that will help children and families achieve their healthiest potential. 
The data collected indicates that more efforts need to be targeted at older children and adolescents, based on the fact that older children in the study reported lower levels of FVC, and substantially higher BMIs. Resources such as the websites: www.fruitsandveggiesmorematters.org and www.freshforkids.com both offer valuable information on creative ways to encourage children and families to increase their FVC. For example, Fruits and Veggies More Matters, has educational materials available to help families understand how to select and store produce, how to create their own sustainable garden, and how to prepare snack and meals with fruits and vegetables as the base. It also has games and activities that teach children the importance of FVC, and how children can help in meal preparation. These resources are especially valuable in Louisiana where children continue to be at a disadvantage in terms of maintaining adequate nutritional levels and a healthy weight.

Another powerful tool would be to increase FVC at school. The USDA requires that all schools in the nation serve fruits and vegetables with every meal during the school day. For many low income children, the majority of their meals for the week are eaten while in school(Friend, Fulkerson, Neumark-Sztainer, Garwick, Flattum, \& Draxten, 2015). Previous studies have found that during school hours, students in pre-kindergarten through elementary consume between one and two of the daily recommended servings of fruits and vegetables (Bourke, Whittaker, \& Verma, 2014; Mullie, Clarys, De Ridder, Deriemaeker, Duvigneaud, \& Hebbelinck, 2006; Struempler, Parmer, Masterpietro, Asiwalla,\& Bubb, 2014). If future interventions reached out to schools, they would have direct access to a great majority of the population of interest, of which they could work to ensure received more fruits and vegetables at every school meal. School lunch programs would provide children with healthier food options than what they would normally find elsewhere by determining what foods are offered and how they are prepared. FCS Educators would also have the unique opportunity to educate children on the benefits of proper FVC using fun and interactive methods such as cooking demonstrations that the children could do at home with family.

The key to combating obesity among children in Louisiana is within grasp, and by increasing FVC at school, the state would provide its youth with the opportunity to overcome one of the most fatal diseases to plague the $21^{\text {st }}$ century.

\section{References}

Cawley J., \& Meyerhoefer C. (2012). The medical care costs of obesity: An instrumental variables approach. Journal of Health Economics, 31(1),219-230.

Center for Disease Control. (2015). Overweight and obesity. Retrieved from https://www.cdc.gov/obesity/index.html

Davison, K., \& Birch, L. (2001). Childhood overweight: A contextual model and recommendations for future research. Obesity Reviews, 2(3), 159-171.

Fresh for Kids. (2018). About fresh for kids. Retrieved from https://freshforkids.com.au/

Friend, S., Fulkerson, J. A., Neumark-Sztainer, D., Garwick, A., Flattum, C. F., \&Draxten, M. (2015). Comparing childhood meal frequency to current meal frequency, routines and expectations among parents. Journal of Family Psychology, 29(1), 136-140.

Fruits \& Veggies More Matters. (2018). Eat more: Fill half your plate with fruits and veggies. Retrieved from https://www.fruitsandveggiesmorematters.org/

Glen, K., Thomas, H., Loebach, J., Gilliland, J., \&Gobert, C. (2013). Fruit and vegetable consumption among children in a socioeconomically disadvantaged neighbourhood. Canadian Journal Of Dietetic Practice \& Research, 74(3), 114-118.

Mullie, P., Clarys, P., De Ridder, D., Deriemaeker, P., Duvigneaud, N., \&Hebbelinck, M. (2006). Breakfast frequency and fruit and vegetable consumption in Belgian adolescents: a cross-sectional study. Nutrition \& Food Science, 36(5), 315-326.

National Center for Children in Poverty. (2016). Louisiana demographics of poor children. Retrieved from http://www.nccp.org/profiles/LA_profile_7.html

National Center for Education Statistics. (2016). Spreadsheet of elementary schools' data. Retrieved from http://elementaryschools.org/

Neville, C., McKinely, M., \&Draffin, C. (2015). Participating in a fruit and vegetable intervention trial improves longer term fruit and vegetable consumption and barriers to fruit and vegetable consumption: a follow-up of the ADIT study. International Journal of Behavioral Nutrition \& Physical Activity, 12,1-7.

Ogden, C. L., Carroll, M. D., Kit, B. K., \&Flegal, K. M. (2014). Prevalence of childhood and adult obesity in the United States, 2011-2012.JAMA: Journal of the American Medical Association, 311(8), 806-814.

Puhl, R., \& King, K. (2013). Weight discrimination and bullying. Best Practice Research in Clinical Endocrinology \& Metabolism, 27, 117-127, doi:10.1016/201212 
Singh, G. K., Kogan, M. D., \& Van Dyck, P. C. (2010). Changes in state-specific childhood obesity and overweight prevalence in the united states from 2003 to 2007. Archives of Pediatrics \& Adolescent Medicine, 164(7), 598607.

Strauss, R. S. (2000). Childhood obesity and self-esteem. Pediatrics, 105, 15.

Struempler, B., Parmer, S., Masterpietro, L., Asiwalla, D., \&Bubb, R. (2014). Changes in fruit and vegetable consumption of third-grade students in Body Quest: Food of the Warrior, a 17-Class Childhood Obesity Prevention Program. Journal of Nutrition Education and Behavior, 46(4), 286-292.

U.S. Department of Agriculture and U.S. Department of Health and Human Services. (2010). Dietary guidelines for Americans, 7th Edition. Washington, DC: U.S. Government Printing Office.

Wang, G.,\& Dietz, W.H. (2002). Economic burden of obesity in youths aged 6 to 17 years: 1979-1999.Pediatrics, 109, 1195-1203.

Williams, N., Fournier, J., Coday, M., Richey, P., Tylavsky, F., \& Hare, M. (2013). Body esteem, peer difficulties, and perceptions of physical health in overweight and obese urban children ages 5 to 7 years.Child: Care, Health and Development, 39(6), 825-834. 